Archived version from NCDOCKS Institutional Repository http://libres.uncg.edu/ir/asu/

McEvoy, David. (2013). Enforcing Compliance with International Environmental Agreements using a Deposit-Refund System. International Environmental Agreements: Politics, Law and Economics, 13(4):

481-496. Published by Springer www.springer.com (ISSN: 1567-9764) DOI: 10.1007/s10784-013-9209-2

\title{
Enforcing compliance with international environmental agreements using a deposit-refund system
}

\author{
David M. McEvoy
}

\begin{abstract}
Whether nations are able to cooperatively manage shared resources through international environmental agreements (IEAs) depends on whether compliance with voluntary commitments can be enforced. Given that nations are sovereign enforcing compliance with IEAs cannot rely on the presence of a strong sanctioning body. Nonetheless, enforcement provisions must be effective in the sense that they will deter noncompliance and credible in the sense that they will actually be imposed. In this paper, we address the problem of enforcing compliance with IEAs by examining one promising mechanism-a deposit-refund system - that exhibits the necessary features for effective enforcement. We analyze a simple model to demonstrate the desirable properties of the mechanism and then consider the effects of imperfect monitoring, uncertainty, partial participation and reputation on the effectiveness of a deposit-refund system.
\end{abstract}

\section{Keywords}

International environmental agreements; Enforcement; Compliance; Deposit-refund

$\begin{array}{ll}\text { Abbreviations } \\ \text { IEAs } & \text { International environmental agreements } \\ \text { GDP } & \text { Gross domestic product } \\ \text { SGP } & \text { Stability and growth pact } \\ \text { CFCS } & \text { Chlorofluorocarbons } \\ \text { CITES } & \text { Convention on International Trade in Endangered Species } \\ \text { MAC } & \text { Marginal abatement cost } \\ \text { UNFCCC } & \text { United Nations Framework Convention on Climate Change }\end{array}$




\section{Introduction}

Whether nations can collectively manage shared natural and environmental resources through international environmental agreements (IEAs) depends largely on whether they can enforce compliance with their commitments. The present challenge of thwarting global climate change highlights this point very clearly. The Kyoto Protocol, currently the only binding agreement restricting greenhouse gas emissions, has been largely unsuccessful in part because the signatories to the agreement have little incentive to meet their individual emissions targets (Barrett 2008). While enforcement mechanisms are imperative for meaningful international cooperation, the nature of voluntary negotiations among sovereign states rules out more traditional regulatory approaches (e.g., emissions abatement mandates). Rather, provisions for enforcement must be decided collectively and, because of sovereignty, enforcing compliance cannot rely on the presence of a strong sanctioning body. Furthermore, the enforcement provisions need to be effective in the sense that they will be severe enough to deter non-compliance and credible in the sense that they will actually be imposed. In this paper we, address the problem of enforcing compliance with IEAs by examining one promising mechanism - a deposit-refund system - that appears to exhibit the necessary features for effective enforcement. A general version of the deposit-refund mechanism explored here has recently been proposed in the theoretical economics literature (Gerber and Wichardt 2009), and the reported results are encouraging in terms of its effectiveness at facilitating international cooperation. This paper presents an economic critique of a similar deposit-refund system applied specifically to global-scale international environmental agreements. We analyze a simple model to demonstrate the desirable properties of the mechanism and then provide an economic critique of some practical concerns.

While deposit-refund systems are implemented in a number of more simplistic settings (e.g., return of recyclable solid waste), we analyze a deposit-refund mechanism within an international environmental agreement. The basic mechanism is straightforward, and its most critical element is that parties are able to deposit funds in escrow within a neutral third-party financial institution. As a starting point, consider a negotiated treaty that has defined emissions abatement commitments for each party as well as a defined minimum number of countries required to ratify for entry into force. 2 Once the treaty is open for ratification, parties must decide independently whether to join and become signatories to the IEA. As part of the ratification process, each member is required to pay an initial deposit to a neutral, third-party financial institution. The deposit amounts, like emission abatement commitments, are defined before the ratification period. The IEA enters into force if enough countries ratify (and pay deposits) to satisfy the minimum participation requirement. If the participation requirement is not satisfied, then all deposits are returned and no agreement enters into force.

Following entry into force, IEA members then decide whether to comply with their commitments (i.e., they choose their emissions levels). When the compliance period (e.g., the first commitment period under the Kyoto Protocol) ends, abatement decisions are monitored and the third-party financial institution pays back the deposit if the 
member country is found in compliance.3 Otherwise, if an IEA member is determined in violation of the treaty, the country forfeits all or a fraction of their deposit. If deposit amounts are set to exceed the expected cost of compliance for signatories, the system is expected to motivate full compliance by its members. The deposit-refund system does not require strong sanctioning institutions in the sense that it is not necessary to extract financial resources from a non-compliant country ex post (e.g., through fines or taxation). Rather, the neutral institution simply has to withhold the initial deposit.

In our setting, the deposit-refund system is similar to performance bonds that are levied to ensure fulfillment of environmental obligations. An example is the Surface Mining Control and Reclamation Act (1977) which requires firms to purchase bonds before attaining the permits to begin a mining project. The bond amounts are refunded if the mined land is adequately reclaimed. Performance bonds are also used in the management of timber, oil and gas industries. While deposit-refunds/performance bonds, to our knowledge, have not been included as compliance provisions in environmental agreements, the fact that similar systems are used in other environmental policy dimensions suggests that such mechanisms may be effective.

Although a deposit-refund system has not yet been implemented within an IEA, the mechanism has received some recent attention. The idea was initially mentioned briefly by Finus (2008) in a paper on credible enforcement with IEAs. Shortly after, Gerber and Wichardt (2009) developed a general theoretical model in the public economics literature, finding that under certain conditions a deposit-refund can motivate efficient public-good provision. More recently, Hovi et al. (2012) discuss broadly how such a mechanism can be used to maintain compliance with a climate agreement, and Cherry and McEvoy (2013) designed a series of experiments to test the predictions from Gerber and Wichardt. We add to this particular segment of the literature in two fundamental ways. First, we analyze the properties of the deposit-refund mechanism within a well-established model of international environmental agreement formation among heterogeneous countries. Second, we relax some of the more restrictive assumptions of the standard model and consider the effects of imperfect monitoring, partial participation, uncertainty and reputation on the effectiveness of the enforcement mechanism.

\section{The problem of enforcing compliance with IEAs}

Compliance with international environmental agreements must be enforced. Although in some cases compliance may be achieved through informal enforcement mechanisms, in practice, provisions for enforcing compliance are included in many IEAs. 5 The problem is that with many treaties these provisions cannot sufficiently deter noncompliance. For example, consider the limitations of the enforcement mechanism implemented under the Kyoto protocol. The enforcement provisions were adopted in Marrakesh during the seventh conference of the parties in 2001. Specifically, the provision states that if a country is deemed non-compliant after the first commitment period of the Protocol (2008-2012), then they are required to abate the difference between their observed emissions and their assigned emissions plus an additional $30 \%$ 
of the deficit during the second commitment period. This penalty (emissions reduction) is in addition to its defined commitments during the next period. In other words, the penalty imposed for falling short of their emissions target is to increase the amount of abatement a signatory is responsible for during the next commitment period. It is hard to conceive of a more ineffective punishment strategy. Since countries can put off abatement activities indefinitely, under Kyoto's enforcement provision signatories have incentives to be non-compliant indefinitely. Moreover, non-compliant signatories can opt out of subsequent commitment periods to the Kyoto Protocol, thus avoiding the sanction. 6 In fact, many attribute the impending failure of the Kyoto Protocol to the lack of credible enforcement of compliance. Barrett (2003, p.360) argues, "...if the negotiators had reflected on the need for enforcement and on the difficulty of devising an effective enforcement mechanism earlier in the process, they may have negotiated a different kind of treaty-one that sustained more cooperation."

One of the most storied IEAs at the global scale is the Montreal Protocol on Substances that Deplete the Ozone Layer (or simply the Montreal Protocol). It entered into force in 1989 and is considered by many as one of the most impressive examples of large-scale international cooperation. The treaty required developed nations (Annex A countries) to immediately begin eliminating the use and sale of chlorofluorocarbons (CFCs) and other ozone-depleting substances and required developing nations to begin a slow phase-out of these substances. The provision for enforcing compliance with the Montreal Protocol is much different than that of the Kyoto Protocol. The parties to the treaty, at their fourth meeting, decided upon a list of measures that may be taken in response to noncompliance with the Protocol. These included "carrots" in the form of technological and financial assistance as well as "sticks" in the form of trade sanctions and suspension of other rights under the Protocol. How much of the apparent success of the Montreal Protocol can be attributed to its enforcement mechanism, however, is unclear without counterfactual evidence on compliance levels in the absence of the provision (Benedick 1998).

The threat of trade sanctions to enforce compliance is employed in other IEAs, notably the Convention on International Trade in Endangered Species (CITES). Although it appears that trade sanctions have been used successfully to enforce compliance (and participation) with IEAs, such sanctions may not be conducive to every agreement. The credibility of trade sanctions is questionable since they require signatories to unilaterally impose restrictions as they see fit. Thus, the type and severity of the punishment will vary between member countries (Barrett 2008). Indeed, it is possible that a secondorder freeriding problem exists with trade restrictions as some countries may rely on others to bear the cost of imposing sanctions.

Agreements may also rely on more informal enforcement strategies (Keohane 1986). For example, nations employing a strategy of "conditional cooperation" will comply with their commitments only if other parties do the same. However, for the most part enforcement provisions included in IEAs are either not severe enough to deter noncompliance (e.g., the provision under the Kyoto Protocol) or the sanctions are not credible in the sense that they are unlikely to be imposed. Chayes and Chayes (1995, p. 
33) bear this narrative out by arguing that the fundamental problem with sanctions included as part of existing IEAs is that employing them "entails high costs to the sanctioner." In other words, trade sanctions and other reciprocal strategies require that the parties themselves incur the cost of sanctioning, and therefore, the sanctions are not credible. On the other hand, the enforcement mechanism under Kyoto can only be effective given a strong regulatory body that can mandate emissions control policies. Sovereignty, of course, precludes this possibility, and thus, the need to explore alternative enforcement strategies.

Here, we examine a deposit-refund to enforce compliance with an IEA. The mechanism is credible in the sense that it does not rely on signatories to voluntarily impose costly sanctions, and it does not rely on an enforcement body to extract financial resources from a non-compliant country ex post. This study adds to the previous analytical literature on enforcing compliance with IEAs (e.g., Carraro and Siniscalco 1993; Folmer et al. 1993; Barrett 1994, 1997, 2008; Carraro and Botteon 1997; Carraro and Siniscalco 1997; Hoel and Schneider 1997; Botteon and Carraro 1998; Finus and Rundshagen 1998; Barrett and Stavins 2003; Hovi et al. 2007; Finus 2008; McEvoy and Stranlund 2009). 8 In the next section, we develop a simple model of international emissions abatement in order to demonstrate how a deposit-refund system functions within an IEA. We present the results of the model, and then, in the section that follows, consider the effects of imperfect monitoring, uncertainty, partial participation and reputation on the effectiveness of the enforcement mechanism.

\section{A model of an IEA with heterogeneous countries}

To analyze how a deposit refund is incorporated within an IEA, we adopt with the wellknown model from Barrett (1994) and McGinty (2007) from the non-cooperative game

\section{Fig. 1 Country i's marginal benefit and cost of emissions abatement}

theory literature. We choose this model because it clearly illustrates the inherent freerider problem within international agreements by structuring the relationship between countries as a prisoners' dilemma. Let $N=\{1, \ldots, n\}$ denote the set of asymmetric countries. Following Barrett (1994) and McGinty (2007) global benefit from emissions abatement is assumed to be a concave function $B(Q)=b\left(a Q-Q^{\wedge} 2 / 2\right)$ that depends on the worldwide quantity of emissions abatement $Q=\sum_{i=1}^{N}$ qi; where qi is country i's abatement level.9 Parameters $\mathrm{a}$ and $\mathrm{b}$ are positive. Country i receives benefit share $\alpha_{i}$, where $\alpha_{i} \in(0,1)$ and $\sum_{i=1}^{N} \alpha_{i}=1$. Therefore, the total benefit of abatement for country i is $\mathrm{Bi}(\mathrm{Q}, \mathrm{ai})=\operatorname{aib}\left(\mathrm{aQ}-\mathrm{Q}^{\wedge} 2 / 2\right)$ and the marginal benefit of abatement is

$$
B_{i}^{\prime}=\alpha_{i} b\left(a-\left(q_{i}+Q_{-i}\right)\right),
$$

where Q-i denotes the aggregate abatement level of the other $\mathrm{N}-1$ countries. Abatement cost functions are assumed to be convex for all countries and take the form 
$\mathrm{Ci}(q i, \mathrm{ci})=\operatorname{ciqi}^{\wedge} 2 / 2$. Thus, the marginal abatement cost (MAC) for country $i$ is

$$
C_{i}^{\prime}=c_{i} q_{i}
$$

In a non-cooperative game, country i chooses qi by equating (1) and (2) which yields

(3)

$$
q_{i}^{R}=\frac{\alpha_{i} b\left(a-Q_{-i}\right)}{c_{i}+\alpha_{i} b},
$$

where the superscript $R$ denotes a country's reaction function. A country's reaction function is increasing in the size and share of the benefit of abatement and decreasing in the individual cost of abatement and the level of abatement provided by the $(\mathrm{N}-1)$ other countries. The joint solution to the $\mathrm{N}$ countries' reaction functions yields the noncooperative equilibrium abatement level for country i, which we denote as $q_{i}^{\text {nc }}$. Figure 1 illustrates Eqs. (1) and (2) and $q_{i}^{\text {nc }}$ for country i. The figure is drawn by fixing aggregate abatement of the other $\mathrm{N}-1$ countries at their equilibrium non-cooperative level, denoted as $Q_{-i}^{\mathrm{nc}}$.

Because abatement by one nation results in a positive externality that benefits the other $\mathrm{N}-1$ nations, maximizing social welfare requires that the abatement externality is internalized. The welfare-maximizing level of abatement is the result of joint maximization of each individual country's net benefit function. The welfare-maximizing level, which we denote as qi*, is derived formally in McGinty (2007). The important relationship is that $\sum_{i=1}^{N} q_{i}^{*}>\sum_{i=1}^{N} q_{i}^{\text {nc }}$, and thus, maximizing social welfare requires more abatement than the non-cooperative outcome. Thus, it is possible that countries can improve joint welfare by increasing emissions abatement through an international environmental agreement.

\subsection{An IEA with a deposit-refund system}

Consider an international environmental agreement that forms over two stages. In the first stage (the participation stage), countries decide whether to ratify and become signatories to the agreement. When making the decision to ratify, each country faces a defined emission abatement commitment of $\bar{q}_{i}$ where $q_{i}^{\text {nc }}<\bar{q}_{i}$. Therefore, the emissions abatement requirement for country i under the IEA is strictly greater than the unilateral management level. When making the decision to ratify, countries also face a minimum participation requirement, denoted as $\mathrm{sp}$, that specifies the minimum number of countries required for entry into force.11,12 Following Gerber and Wichardt (2009), we consider the case in which entry into force requires the grand coalition, that is, $s p=$ N.13 Throughout, _qi and sp are chosen so that IEAs are profitable for the members. Profitability requires that if at least $\mathrm{sp}$ countries ratify the IEA, and each member country 
abates its required amount of emissions, then a member earns more under the IEA compared to the non-cooperative outcome.

As part of the ratification process, each country is required to pay a deposit of amount di to a neutral third-party institution. If the agreement does not receive enough signatories to satisfy the minimum membership requirement, then the deposit amounts are immediately returned and an IEA does not form. Otherwise, if enough countries ratify (and pay deposits) to satisfy the minimum membership requirement, then the IEA enters into force and the members are bound to their commitments. In stage two (the compliance stage), member countries make their emissions abatement decisions. At the end of the compliance stage, a member country's abatement activities are monitored and their compliance level is determined. If qi _ qi, then a country is deemed compliant and is refunded the total amount di. Otherwise, if qi _ qi, then a country is in violation of its agreement and will forfeit all or a portion of its deposit (described in more detail below). We start with an analysis of the compliance stage.

If nations reach the compliance stage, then an agreement of size sp has formed and each member country has paid their deposit. In this stage, the members must make their emissions abatement decision. Whether a country chooses to comply with the agreement depends on the relative costs and benefits of compliance. Because qnc i \_qi compliance requires abatement beyond the individually welfare-maximizing level, and thus, compliance is necessarily costly.

Perhaps surprisingly, the cost of complying with an IEA increases as the abatement activities of the other $\mathrm{N}-1$ countries increase. To see this, consider how country i's marginal benefit function changes with increases in other countries' abatement levels. Figure 2 illustrates a change in the marginal benefit function when Q-i is fixed at the non-cooperative equilibrium level compared to when it is fixed at the level of abatement when all other members are fully compliant with their commitments under an IEA, $\bar{Q}_{-i}$. Since $\bar{Q}_{-i}>Q_{-i}^{\text {nc }}$ the marginal benefit function of country i shifts downward given any positive level of compliance (i.e., abatement beyond the non-cooperative level) by the other members. This causes i's optimal level of emissions abatement to decrease under an IEA relative to $q_{i}^{\text {nc }}$.

This relationship is clear from country i's reaction function in Eq. (3) which decreases with increases in abatement from other countries. Therefore, the appropriate baseline level of emissions to use when estimating the cost of compliance with an IEA is not the unilateral management abatement level, but rather an abatement level strictly less than that and bounded below by the level realized if all other countries comply with their agreements (denoted as qi B). In Fig. 2, the cost of compliance with an IEA is bounded from below by $b$ (if no other country abates beyond the non-cooperative level) and from above by $a+b+c$ (if all other countries fully comply).

We can derive the expression for a country's marginal compliance cost by subtracting its marginal benefit of abatement from its marginal abatement cost: 


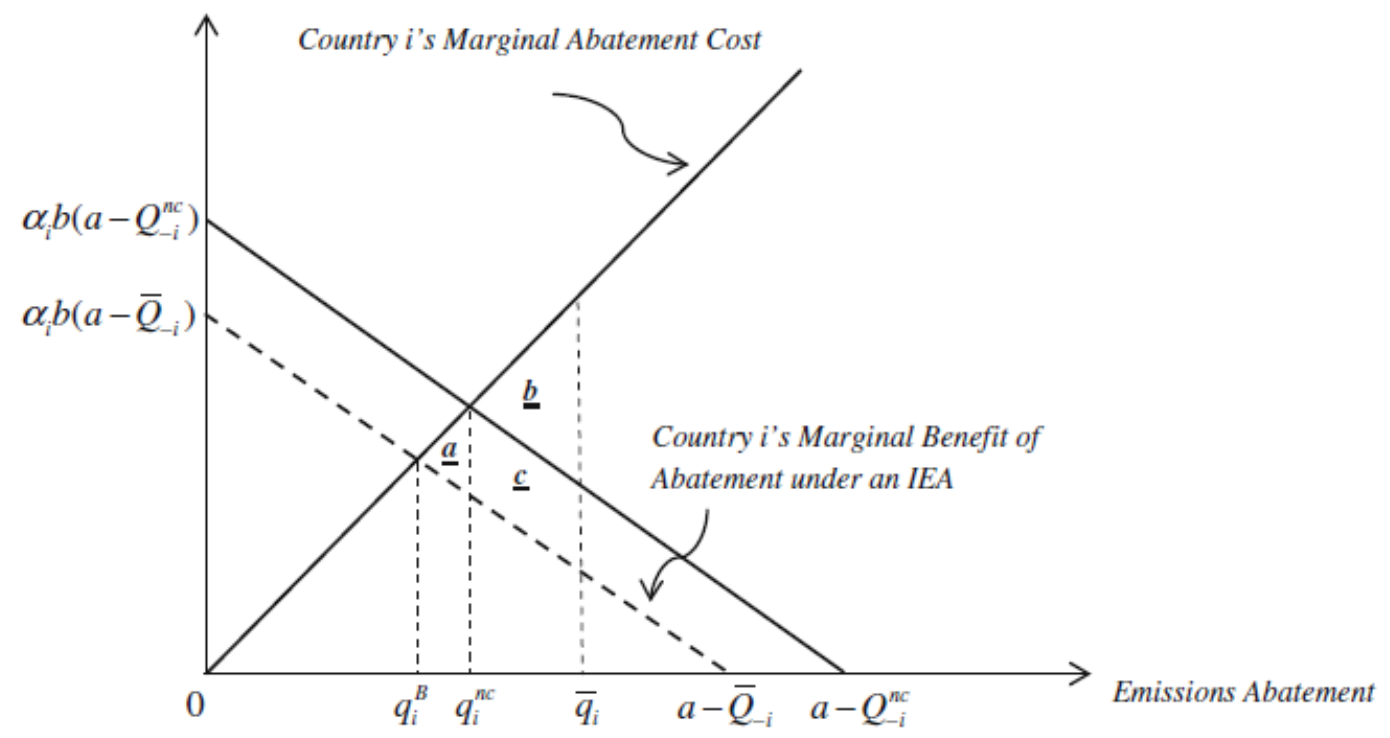

Fig. 2 Country i's cost of compliance under an IEA

From (4), the marginal cost of compliance is decreasing in the overall benefit to abatement and its share of the benefit and is increasing in the cost of abatement and the cumulative level of global abatement.

A member's total cost of compliance with an IEA that achieves full compliance is

\section{(5)}

$$
C C_{i}=\int_{q_{i}^{\mathrm{B}}}^{\bar{q}_{i}} c_{i} q_{i}-\alpha_{i} b\left(a-\left(q_{i}+Q_{-i}\right) \mathrm{d} q_{i},\right.
$$

which corresponds to area a ? b ? c in Fig. 2. A member will comply with the IEA if and only if the benefits from compliance exceed the cost of compliance. Under the depositrefund system, the benefit from compliance is the return of the deposited amount. Therefore, to achieve full compliance, deposits must be set so that di C CCi. If, after country i's emissions abatement decision, qi _qi, then a firm is deemed compliant and is refunded the total amount di.15 Otherwise, if qil_qi, then a country is in violation of its agreement and will forfeit its deposit. Clearly if di $\mathrm{C} C \mathrm{Ci}$, then i will fully comply with their commitments. However, in practice, the treaty must also specify whether a non-compliant country loses all or only a portion of their deposit. Losing the entire deposit in response to any level of non-compliance is incentive compatible, but perhaps extreme. This could be resolved by a system in which deposit amounts are returned in proportion to the member country's level of compliance. Formally, for an abatement choice of qi < qi, a member country will be refunded an amount weakly 
greater than $\int_{q_{i}^{\mathrm{B}}}^{q_{i}} c_{i} q_{i}-\alpha_{i} b\left(a-\left(q_{i}+Q_{-i}\right) \mathrm{d} q_{i}\right.$. The key element being that the amount a member country is refunded must be weakly greater than their respective cost of compliance. Since ci and qi will likely differ across the $\mathrm{N}$ countries, incentive compatible deposit amounts will also differ.

Given that deposits paid in the participation stage are incentive compatible, members are expected to fully comply with their commitments in the compliance stage. In the participation stage, countries decide simultaneously whether to join the IEA. Although emissions abatement commitments and required deposit amounts differ across countries, given that the vector of deposit amounts satisfies di > CCi for all i, all countries are expected to comply in stage two. Since_q and sp are chosen so that IEAs are profitable, and since participation from all countries is required for entry into force, all countries are expected to join in the participation stage and fully comply with the agreement in the compliance stage. Therefore, a well-crafted deposit-refund system can motivate a desired level of participation and full compliance with an international agreement on the environment.

\section{A critical discussion of the deposit-refund system}

The simple static model presented in section three is useful for demonstrating how a deposit-refund system functions and how optimal deposit amounts are determined. The model, necessarily, abstracts away from important practical concerns of implementing a deposit-refund system. In this section, we discuss some of those concerns.

\subsection{Deposits}

The deposit-refund system requires the existence of a third-party institution capable of holding and disbursing financial deposits. Although the deposit-refund feature is unique to IEAs, the creation of third-party financial institutions to support international cooperation is not novel. For example, the Multilateral Fund was created under the Montreal Protocol to facilitate financial exchange between developed and developing countries. The fund facilitates compliance by aiding developing countries with the cost of reducing their dependency on ozone-depleting substances. The financial institution under a deposit-refund system would work entirely different. The institution would manage escrow accounts in which monies will be disbursed given the fulfillment of contractual emissions abatement responsibilities. Ratification of the IEA would serve as a binding contract to the escrow. It would be expected that deposit holdings collect interest from a risk-free investment that has a life span equivalent to the timing of commitment periods. Unlike our static model from section three, IEAs are likely to have commitment periods that span many years. For example, the first commitment period under the Kyoto Protocol lasts from 2008 to the end of 2012. While it is possible to require a lump-sum deposit sufficient to cover the entire cost of compliance over a commitment period, it is perhaps more reasonable to require incremental deposits. For example, if di > CCi is satisfied with a deposit amount of 200 billion U.S. Dollars, a country could make five annual deposits of 40 billion (assuming, for simplicity, a discount rate of zero) for compliance to be incentive compatible. Provided that existing 
deposited amounts are lost if additional deposits are not made, the mechanism holds its desirable properties. Incremental deposits are also more flexible in the sense that annual deposit amounts may be adjusted given changes in compliance cost estimates.

The actual size of the deposit, of course, depends on the member country's abatement responsibilities and its corresponding cost of compliance. That said, to provide a rough idea of the size of these deposits, we consider estimates of compliance costs for the United States under the Kyoto Protocol. According to a report by the Energy Information Administration (1998), the Emissions Prediction and Policy Analysis Model developed by researchers at the Massachusetts Institute of Technology estimates that the cost for the United States to comply with the Kyoto Protocol (a $7 \%$ reduction in 1990 level emissions) ranges from 0.5 to $1.5 \%$ of GDP in 2010. The report estimates this percentage loss, using 1996 dollars, to be between \$52 billion and \$156 billion in 2010 . Thus, if using the upper-bound estimate from this example study, the United States would require a deposit greater than $\$ 156$ billion to motivate full compliance with Kyoto. However, given such a broad range of compliance costs in this single study, it is clear that uncertainty will play a nontrivial role in determining optimal deposits and whether the deposit-refund system holds its desirable properties (we explore uncertainly later in this section). The report also includes compliance cost estimates for the United States from five other studies. Estimates range from $\$ 52$ billion to $\$ 437$ billion (4.2 \% of 2010 GDP). These estimates were made without accounting for the possibility of emissions trading, sinks, offsets or the Clean Development Mechanism, and therefore, the estimates likely overestimate abatement costs with Kyoto.

In theory, an optimal deposit-refund system motivates full compliance by the parties to the IEA, and therefore obviates the need to address the question of what to do with withheld deposits. In reality, the practical question of what to do with a positive deposit balance must be addressed. In terms of maintaining incentive compatible deposits, the most important concern is that the deposit amounts are not disbursed in a way that distorts the marginal incentives to comply with the agreement. A simple way to achieve this is to use the remaining deposits to fund the provision of other global public goods that are not directly tied to the resource managed under the IEA.

\subsection{Monitoring for compliance}

Thus far the analysis has assumed that an IEA member country's emissions level (and therefore compliance level) can be monitored completely and accurately. This of course is an oversimplification. Monitoring global emissions, of any kind, is necessarily prone to inaccuracies. In most cases, members' compliance levels with IEAs are determined through self-reports. For example, monitoring of compliance with the Kyoto Protocol is the responsibility of the Enforcement Branch of the Compliance Committee established under the Marrakesh Accords. Annex I Parties to Kyoto are required to submit annual greenhouse gas inventories to the Enforcement Branch for review. The committee audits the reports and makes a conclusion as to whether the reporting country is in compliance. Clearly, in the absence of sanctions in response to violating a treaty, parties have incentives to break their commitments and falsely report that they are in 
compliance. In contrast, under a deposit-refund system the sanction is well defined; that is, a non-compliant member forfeits their deposit amount (or an amount proportional to their level of non-compliance). However, because monitoring for compliance will likely be, in some degree, incomplete or inaccurate, a country is likely to weigh their expected sanction imposed in response to noncompliance (i.e., the probability of being found noncompliant times the deposit) with the benefit of non-compliance (i.e., the savings in abatement costs). Both Type I and Type II errors are possibilities given the realities of inaccurate monitoring. A Type I error results when a monitoring body falsely concludes that a non-compliant party is under compliance. On the other hand, a Type II error describes a situation in which a compliant country is falsely determined non-compliant. Most IEAs include provisions to limit the extent of Type II errors, so they are likely to play only a minor role.16 It is more likely that the positive probability of a Type I error influences the compliance decision of a member country. When Type I errors are possible, the benefit from non-compliance increases relative to when monitoring is perfectly accurate. Therefore, incentive compatible deposit amounts will need to be higher given Type I monitoring errors in comparison with the baseline case that assumes complete and accurate monitoring.

\subsection{Uncertainty in the benefit-cost ratio}

An additional challenge with implementing a deposit-refund system within an IEA is that the deposits are paid upon ratification but compliance decisions are made in the future. In that time, it is possible that the costs and benefits of compliance change, and, as a result, deposits that were incentive compatible at ratification may be insufficient at the time of compliance. This is problematic in particular if the cost of compliance emerges to be significantly higher than expected because signatories may then find it profitable to violate the terms of the agreement and forfeit their deposits.

To illustrate, denote the benefit-cost ratio for country $\mathrm{i}$ as $\mathrm{ci}=\mathrm{b} / \mathrm{ci}$. The marginal compliance cost from Eq. (4), following Kolstad (2007), can now be expressed as

$$
C_{i}^{\prime}-B_{i}^{\prime}=q_{i}-\alpha_{i} \gamma_{i}\left(a-\left(q_{i}+Q_{-i}\right) .\right.
$$

From (4a) it is clear that the marginal cost of compliance is decreasing in the benefitcost ratio. Let us now assume that there are two states of the world, one with a high benefit-cost ratio $\left(\gamma_{i}^{\mathrm{H}}\right)$ and one with a low benefit-cost ratio $\left(\gamma_{i}^{\mathrm{L}}\right)$, which occur with the following probabilities, $p$ and $1-p$, respectively. When making the decision to join an IEA, a country is informed about the two potential states of the world and their respective likelihoods. However, which state of the world will transpire is not revealed until the compliance stage. To make clear comparisons between this model and the one without uncertainty from section three, assume that $\pi \gamma_{i}^{\mathrm{H}}+(1-\pi) \gamma_{i}^{\mathrm{L}}=\gamma_{i}$ and the deposit amount di is determined by the expected value (i.e., ci). Therefore, when making the decision to join an IEA and pay the deposit in the participation stage, a riskneutral country faces the same incentives as in the model without uncertainty. 
Once in the compliance stage, the total cost of compliance is

\section{(5a)}

$$
C C_{i}=\int_{q_{i}^{\mathrm{B}}}^{\bar{q}_{i}} q_{i}-\alpha_{i} \gamma_{i}^{j}\left(a-\left(q_{i}+Q_{-i}\right) \mathrm{d} q_{i},\right.
$$

where $\mathrm{j}=\mathrm{H}, \mathrm{L}$ depending on the realized state of the world. Nations will comply with the treaty only if the deposit amount is weakly greater than the total cost of compliance. Clearly, if the benefit-cost ratio is high, then the deposit amount will be more than sufficient to motivate full compliance. In this case, this type of uncertainty does not pose a problem. However, if the benefit-cost ratio is sufficiently low, the deposit will not be large enough to motivate compliance with the IEA. The result will be realized abatement levels less than the committed levels under the treaty. With asymmetric countries and compliance costs that depend on aggregate abatement, the total level of emissions abatement achieved under uncertainty will also depend on the expectations of the benefit-cost ratios of the other signatories.

It is not clear, however, whether the possibility of higher-than-expected compliance costs renders the deposit-refund system less desirable. First, if the cost of compliance increases because of a jump in the cost of emissions abatement, the welfare maximizing level of abatement will decrease in response. Without conjecturing whether it is likely, it is nevertheless possible that less abatement is actually desirable. Second, deposits that are too low to encourage compliance with an IEA may be likened to "safety-valves" that are included in many emissions permit markets. In these systems, if the permit market equilibrium price is exceptionally high due to unexpectedly high marginal abatement costs, firms may purchase additional permits from a regulator at a lower fixed price. In a similar spirit, with the deposit-refund system if the cost of abating emissions is unexpectedly high, nations can avoid paying that cost by reducing abatement and forfeiting their deposit.

\subsection{Reputation}

Although not addressed in the model from section three, it is possible that nations may suffer non-pecuniary sanctions from violating an international treaty. For example, meaningful participation with an IEA signals a willingness to cooperate internationally and demonstrates adherence to a cooperative norm. Through compliance, a participating country may build a positive reputation as a cooperative member of a global community. A positive reputation may improve a country's negotiating position in other political dimensions. The flip side of this is that non-compliance with commitments made under an IEA may cause a country's reputation as a cooperating member to deteriorate, and this reputation loss may be costly. 
Positive reputation effects will effectively increase the benefit of abating emissions. To illustrate, Fig. 3 displays a candidate for a country's marginal benefit of abatement with reputation effects (dashed line). The solid line is the now familiar marginal benefit of abatement without reputation effects. Note that, like Fig. 2, the aggregate abatement level of the other $\mathrm{N}-1$ countries is fixed at the full cooperative level under the IEA. In the graph, if a country fully complies with the IEA, it receives the full benefit of a positive reputation (denoted as $r$ ). The total cost of compliance given a positive reputation effect is $a$, whereas the total cost of compliance without a reputation effect is $a+b$.

Abatement beyond the required amount does not enhance the reputation effect above $\mathrm{r}$. On the other hand, if a country becomes in violation of the agreement (i.e., abates less than $\bar{q}_{i}$ ) its reputation effect diminishes until it becomes zero at the baseline level of emissions.

Quantifying the value of a positive reputation as a cooperative member of a global community is likely not achievable. That said, a positive reputation effect may be capable of offsetting small shifts in benefit/cost functions that could result from shifts in supply and/or demand or from uncertainty. Recall, if the marginal cost of emissions abatement is revealed to be higher than was estimated when determining the deposit amount, then the required deposit will be too low to motivate full compliance. In this case, the reputation effect may act as a buffer by increasing the marginal benefit of abatement, perhaps enough to bring a member country under compliance. In short, acknowledging a reputation effect may quell some concerns that deposits will be set too low due to incomplete information during the negotiation stage.

\subsection{Partial participation}

While some IEAs do require the grand coalition to join before entry into force (e.g., Convention for the Protection of the Marine Environment of the North-East Atlantic),

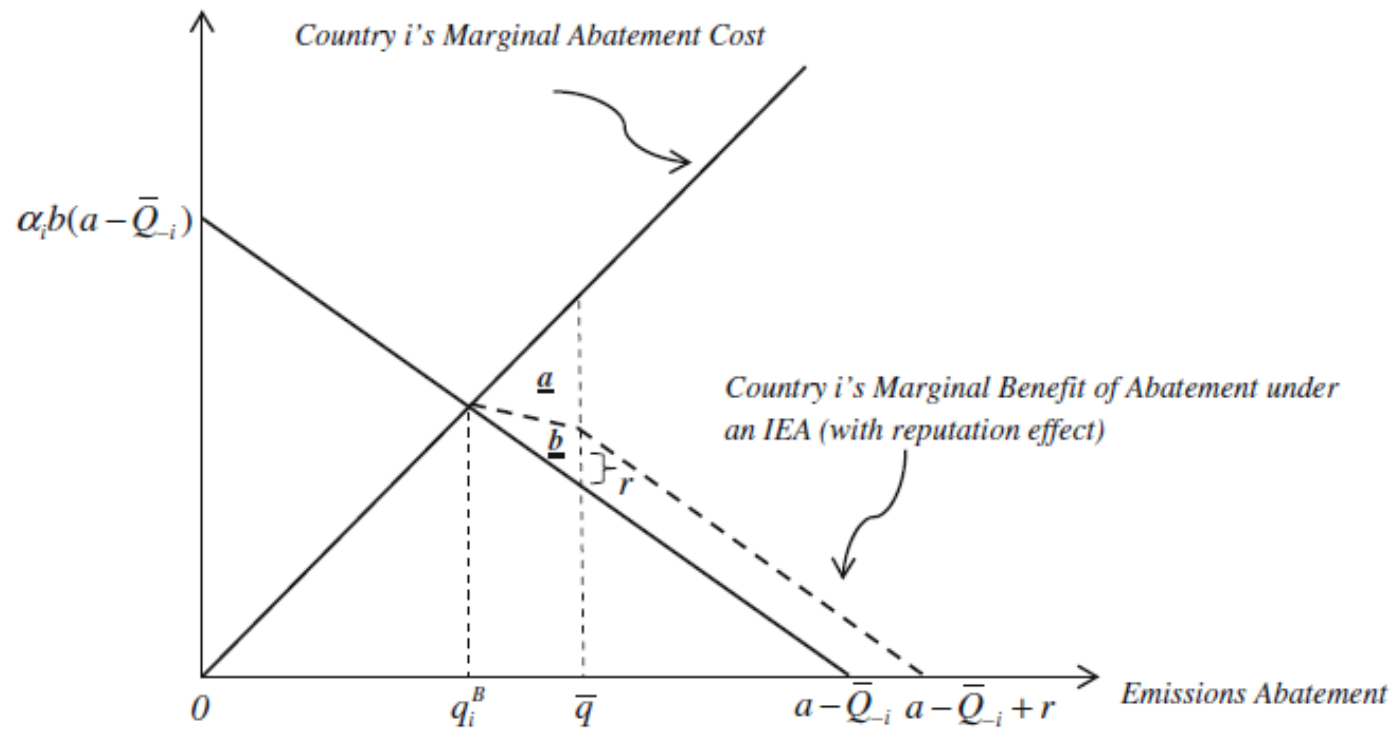

Fig. 3 Cost of compliance under an IEA with reputation effects 
many require only partial participation (e.g., Kyoto and Montreal Protocols). Requiring less than full participation means that members and non-members can coexist.

Regardless of whether an IEA requires full or partial participation, an agreement that enters into force will require its members to take on more emissions abatement than realized in the non-cooperative case (maintaining the condition that $q$ and $s p$ are chosen so that IEAs are profitable). Non-members, of course, are not required to take on abatement activities. In fact, from the reaction function in Eq. (3), non-members will respond to an increase in abatement from IEA members by reducing their own abatement. As members increase abatement above the non-cooperative level, nonmembers reduce abatement below their non-cooperative levels, and therefore, the downward shift in the marginal benefit of abatement caused by an IEA (dashed line in Fig. 2) will be less dramatic when only a subset of countries are required to join. From Fig. 2, this will cause the total cost of compliance with an IEA given partial participation to be weakly less than the cost of compliance given full participation (provided the same level of $\bar{q}_{i}$ ).

The existence of free-riding non-members, however, should not preclude effective IEAs from forming. Again, if agreements are profitable for the members, and deposit amounts are chosen so that compliance is incentive compatible, then there is an incentive for an IEA of sp members to form. Non-members will fare better than members because they enjoy the benefits of increased emissions abatement without incurring the cost. It is possible that the payoff differences between members and non-members could prevent IEAs from forming due to coordination failures. That is, an agreement may fail to form because countries have competing incentives when making participation decisions: on one hand, every country prefers that an IEA forms, and on the other, every country prefers to free ride on that agreement.

It is also possible that equity concerns may exacerbate the difficulties in forming effective IEAs when only a subset of countries are required for entry into force. Again, non-members enjoy the benefit of increased public-good provision without paying the cost. If countries have preferences toward inequitable responsibilities and payoffs, those preferences may prevent otherwise profitable IEAs from forming. Indeed, Kosfeld et al. (2009) demonstrate that inequality aversion can increase the minimum profitable agreement size. This means that minimum participation requirements must be set higher to ensure profitability when countries have preferences toward inequality.

\section{Conclusion}

Whether nations are able to cooperatively manage shared resources through international environmental agreements depends largely on whether members can credibly enforce compliance with their commitments. In the absence of an overarching regulator capable of mandating policies and imposing financial sanctions in response to non-compliance, nations must rely on alternative enforcement mechanisms. In this paper, we critique one promising mechanism-a deposit-refund system-which does not require the presence of a strong sanctioning institution. The mechanism works as follows: Upon ratification, member countries pay a pre-defined deposit to a third-party 
financial institution. If enough countries ratify the IEA to satisfy a minimum participation requirement, then the agreement enters into force. In that case deposits are returned (with interest) if members are deemed in compliance at the end of the commitment period. If a member country is found non-compliant, then all or a portion of their deposit is withheld. If an IEA does not receive enough signatories to enter into force, then all collected deposits are refunded immediately and an effective agreement does not form. The deposit-refund system motivates participation and compliance with an IEA provided that agreements are profitable and that the deposited amount is greater than the realized cost of compliance.

The deposit-refund system does not require strong sanctioning institutions in the sense that it is not necessary to extract financial resources from a non-compliant country after emissions decisions are made (e.g., through fines or taxation). Rather, the neutral institution simply withholds the initial deposit in response to non-compliance. In most cases, it is unrealistic to expect a non-compliant country to pay a financial penalty ex post since they can simply withdraw from an agreement. The deposit-refund system circumvents this issue because the deposits are paid before emissions decisions are made. Therefore, leaving the agreement is likely an undesirable response to detected non-compliance because exit triggers the loss of the deposit.

Moreover, the deposit-refund mechanism does not require that the IEA members themselves pay the cost of enforcing compliance. For example, the threat of trade sanctions in response to non-participation and/or non-compliance requires that IEA members (including compliant countries) restrict trade with violating countries (e.g., Montreal Protocol). Restricting trade is costly for the parties punished, but it is also costly for the punisher. Chayes and Chayes (1995) argue that the fundamental problem with sanctions included in many IEAs is that those imposing them pay a high cost, and as a result, the sanctions are not likely to be implemented. The deposit-refund mechanism avoids this issue altogether.

Our paper contributes to the existing literature on enforcing compliance by developing an analytical model of an IEA with heterogeneous countries under a deposit-refund system. Our paper also addresses the practical issues of incomplete and inaccurate monitoring for compliance with IEAs, uncertainty and the size of required deposits, the effect of reputation on compliance costs and equity concerns on the effectiveness of a deposit-refund system. The mechanism is certainly not flawless. It requires countries to pay substantial sums of money at the front end of an international agreement (possibly larger than $2 \%$ of GDP) while facing great uncertainty. It also relies on a financial institution capable of holding deposits and issuing reimbursements. It should be acknowledged that the creation of a neutral institution with the power to withhold financial deposits from non-compliant parties constitutes an exercise of international governance that is remarkably rare in IEAs. However, a carefully designed depositrefund system is credible, effective and simple to understand. For these reasons, it should be considered seriously as a potential mechanism to enforce compliance with international agreements on the environment. 


\section{References}

Barrett, S. (1994). Self-enforcing international environmental agreements. Oxford Economic Papers, 46(1), 878-894.

Barrett, S. (1997). The strategy of trade sanctions in international environmental agreements. Resource and Energy Economics, 19(1), 345-361.

Barrett, S. (2003). Environment and statecraft: The strategy of environmental treatymaking. Oxford and New York: Oxford University Press.

Barrett, S. (2008). Climate treaties and the imperative of enforcement. Oxford Review of Economic Policy, 24(2), 239-258.

Barrett, S., \& Stavins, R. (2003). Increasing participation and compliance in international climate change agreements. International Environmental Agreements: Politics, Law and Economics, 3, 349-376.

Benedick, R. (1998). Ozone diplomacy: New directions in safeguarding the planet. Cambridge MA and London: Harvard University Press.

Botteon, M., \& Carraro, C. (1998). Strategies for environmental negotiations: Issue linkage with heterogeneous countries. In N. Hanley, \& H. Folmer (Eds.), Game theory and the environment. Cheltenham, and Northampton, MA: Edward Elgar.

Carraro, C. \& Botteon, M. (1997). Burden sharing and coalition stability in environmental negotiations with asymmetric countries. In C. Carraro (Ed.), International environmental negotiations. Cheltenham and Northampton, MA: Edward Elgar.

Carraro, C., Marchiori, C., \& Oreffice, S. (2009). Endogenous minimum participation in international environmental treaties. Environmental \& Resource Economics, 42(3), 411425.

Carraro, C., \& Siniscalco, D. (1993). Strategies for the international protection of the environment. Journal of Public Economics, 52(3), 309-328.

Carraro, C., \& Siniscalco, D. (1997). R and D cooperation and the stability of international environmental agreements. In C. Carraro (Ed.), International environmental negotiations. Cheltenham, U.K. and Northampton, MA: Edward Elgar.

Chayes, A., \& Chayes, A. H. (1991). Compliance without enforcement: State behavior under regulatory treaties. Negotiation Journal, 7(1), 311-330.

Chayes, A., \& Chayes, A. H. (1995). The new sovereignty: Compliance with international regulatory agreements. Cambridge: Harvard University Press. 
Cherry, T., \& McEvoy, D. (2013). Enforcing compliance with environmental agreements in the absence of strong institutions: An experimental analysis. Environmental \& Resource Economics, 54(1), 63-77.

Downs, G. W., Rocke, D. M., \& Barsoom, P. M. (1996). Is the good news about compliance good news about cooperation? International Organization, 50(3), 379-440.

Energy Information Administration. (1998). Impacts of the Kyoto protocol on United States energy markets and economic activity. Resource document. Washington, DC: Office of Integrated Analysis and Forecasting, United States Department of Energy. ftp://eia.doe.gov/service/oiaf9803.pdf. Accessed February 5, 2013.

European Environmental Agency. (2012). Greenhouse gas emissions trends and projections in Europe 2012: Tracking progress towards Kyoto and 2020 targets. Report No 6/2012. http://www.eea.europa.eu/publications/ghg-trends-and-projections2012/at_download/file. Accessed February 5, 2013.1

Finus, M. (2008). The enforcement mechanisms of the kyoto protocol: Flawed or promising concepts. Letters in Spatial and Resource Sciences, 1(1), 13-25.

Finus, M., \& Rundshagen, B. (1998). Toward a positive theory of coalition formation and endogenous instrument choice in global pollution control. Public Choice, 96(1-2), 145186.

Folmer, H., van Mouche, P., \& Ragland, S. (1993). Interconnected games and international environmental problems. Environmental \& Resource Economics, 3(4), 313-335.

Fullerton, D., \& Wolverton, A. (2000). Two generalizations of a deposit-refund system. American Economic Review, 90(2), 238-242.

Gerber, A., \& Wichardt, P. (2009). Providing public goods in the absence of strong institutions. Journal of Public Economics, 93(3-4), 429-439.

Hoel, M., \& Schneider, K. (1997). Incentives to participate in an international environmental treaty. Environmental \& Resource Economics, 9(2), 153-170.

Hovi, J., Froyn, C. B., \& Bang, G. (2007). Enforcing the Kyoto protocol: Can punitive consequences restore compliance? Review of International Studies, 33(3), 435-449.

Hovi, J., Greaker, M., Hagem, C., \& Holtsmark, B. (2012). A credible compliance enforcement system for the climate regime. Climate Policy, 12, 741-754.

Keohane, R. O. (1986). Reciprocity in international relations. International Organization, 40(1), 1-27. 
Kolstad, C. (2007). Systematic uncertainty in self-enforcing international environmental agreements. Journal of Environmental Economics and Management, 53(1), 68-79.

Kosfeld, M., Okada, A., \& Riedl, A. (2009). Institution formation in public goods games. American Economic Review, 99(4), 1335-1355.

McEvoy, D., \& Stranlund, J. (2009). Self-enforcing international environmental agreements with costly monitoring for compliance. Environmental \& Resource Economics, 42(4), 491-508.

McGinty, M. (2007). International environmental agreements among asymmetric nations. Oxford Economic Papers, 59(1), 45-62.

Olivier, J. G. J, Janssens-Maenhout, G., Peters, J. A. H. W.,\&Wilson, J. (2011). Longterm trends in globalCO2 emissions. Report No. 500253004, PBL Netherlands Environmental Assessment Agency. http://edgar.jrc.ec.europa.eu/news_docs/ C02\%20Mondiaal_\%20webdef_19sept.pdf. Accessed February 5, 2013.

United Nations Framework Convention on Climate Change. (2002). Report of the conference of the parties on its seventh session, held at Marrakesh from 29 October to 10 November 2001. Part one: Proceedings Marrakesh.

http://unfccc.int/resource/docs/cop7/13.pdf. Accessed February 5, 2013. 